\title{
Uma análise de relativas livres em posição de sujeito e efeitos de compatibilidade no português brasileiro
}

\section{An analysis of subject free relatives and matching effects in Brazilian Portuguese}

Paulo Medeiros Junior

Universidade de Brasília (UnB), Brasília, Distrito Federal, Brasil.

medeirosjunior33@gmail.com

Resumo: Entende-se que relativas livres sejam sujeitas ao que se chama efeito de compatibilidade, que prevê que a categoria/Caso do sintagmawh integrando essa sentença precisa ser compatível com os requerimentos do predicador da matriz. Alguns estudos como os de Suñer $(1983,1984)$ e Harbert (1983) propõem que relativas livres em posição de sujeito estão livres dos efeitos de compatibilidade em línguas pro-Drop. Os dados do PB parecem contradizer essa ideia; mesmo em posição de sujeito, relativas livres precisam "combinar". Os dados avaliados neste paper, por seu comportamento sintático e semântico, são interpretados não como relativas livres em posição de sujeito, e sim como perguntas indiretas em posição de tópico. A proposta final é a de que o PB é uma língua de $100 \%$ de matching.

Palavras-chave: relativa livre; efeito de compatibilidade; línguas pro-Drop; perguntas indiretas.

Abstract: Free relatives are supposed to be affected by the so-called matching effects, according to which the category/Case of the Whelement integrating this sentence must match the requirements of the matrix predicate. Some works, as the ones by Suñer $(1983,1984)$ and Harbert (1983), have proposed that subject free relatives are free from 
matching effects in pro-Drop languages. Brazilian Portuguese data seem though to contradict this idea; even in subject position, free relatives must match. Focused data are interpreted in this paper (considering their syntactic and semantic behavior) not as subject free relatives, but as topicalized indirect questions. The conclusion is: Brazilian Portuguese is a $100 \%$ matching language.

Keywords: free relative; matching effect; pro-Drop languages; indirect questions.

Recebido em 27 de novembro de 2014.

Aprovado em 21 de março de 2015.

\section{Introdução}

A relativização é um fenômeno comum a todas as línguas humanas e, não por acaso, tem sido objeto de inúmeros estudos nos mais diversos campos da linguística. Questões altamente interessantes de ordem sintática e semântica rondam as construções que derivam desse processo de organização sentencial.

As orações relativas, bipartidas tradicionalmente em restritivas e apositivas, têm, portanto, recebido diversas abordagens de análise a partir de pontos de vista teóricos distintos. ${ }^{1}$ Para além da partição restritiva/ apositiva, apresentam-se as construções que os estudos linguísticos convencionaram chamar orações relativas livres.

Relativas livres são sentenças que compartilham características com orações relativas comuns, mas não se conectam a um antecedente sintático; daí a denominação "livres", por não estarem presas a um núcleo nominal realizado sintaticamente.

\footnotetext{
${ }^{1}$ A esse respeito, conferir trabalhos na perspectiva variacionista como os de Cohen (1981; 1990), Corrêa (1998), Gomes da Silva (2007); abordagens cognitivistas como as de Axt (1992), Choupina (2010) ou da perspectiva da aquisição, como o que se vê em Perroni (2001).
} 
Supõe-se que Relativas Livres (RLs) apresentem (em muitas línguas) algum tipo de preferência, um efeito de conformidade (matching) no que tange a sintagmas-Wh que integram essas estruturas, requerimento que faz com que o operador relativo (ou sintagma-wh) satisfaça os requerimentos de seleção do verbo na oração matriz e do verbo na subordinada.

Assim, entende-se por matching a compatibilidade necessária entre a forma/natureza do sintagma-wh que encabeça relativas livres e os requerimentos da matriz, que são realizados nesse mesmo wh. $\mathrm{O}$ matching tem sido por vezes analisado como uma conformidade categorial ou como uma conformidade de caso. Essa noção é descrita e detalhada logo a seguir.

\section{Requerimento de Compatibilidade (Matching Requirement):}

\section{$\rightarrow$ A Categoria/(C)aso ${ }^{2}$ da palavra-wh na relativa deve combinar com os requerimentos da matriz:}

\section{INGLÊS}

(1) a. He'll reach $\left[{ }_{N P}\left[{ }_{N P}\right.\right.$ whatever height $]$ his father did $]$.

b. He'll get $\left[_{\mathbf{A P}}\left[{ }_{\mathbf{A P}}\right.\right.$ however tall $]$ his father did $]$.

(BRESNAN; GRIMSHAW, 1978)

\footnotetext{
${ }^{2}$ Em Chomsky (1981;1986), propõe-se a oposição caso/Caso para diferenciar a atribuição de caso morfológico e Caso abstrato. O autor formula a hipótese de que, mesmo em línguas sem marcação de caso na morfologia, os SNs (Sintagmas nominais) /DPs (sintagmas determinates) recebem Caso abstrato, sendo esse (o sistema de casos) um universal linguístico. A designação (C)aso remete à possibilidade de se fazer referência a línguas como o alemão (dados em (3)), em que ocorre marcação de caso morfológico, ou a línguas como o português e o inglês, em que - segundo essa visão - se dá a atribuição da Caso abstrato.
} 


\section{PORTUGUÊS}

(2) a. O João só gosta de [ ${ }_{D P}\left[{ }_{D P}\right.$ quem você traz para essas festas]].

b. Ele conversou $\left[_{\mathbf{P P}}\left[{ }_{\mathrm{PP}}\right.\right.$ com quem eu saí $]$. $^{3}$

(MEDEIROS JUNIOR, 2005)

\section{ALEMÃO}
a. Ich folge wem
immer ich vertraue
'I follow who-DAT ever I trust'
b. *Ich folge wen immerich bewundere
'I follow who-ACC ever I adore'

(VOGEL, 2001)

${ }^{3}$ É importante salientar que, a rigor, quanto aos predicadores da matriz em (2) a e b, ambos selecionam PPs (sintagmas preposicionais) como seus complementos; a divisão parentética com a distinção em (2) a. visa a evidenciar que a subordinada, [quem você traz para essas festas], complementa a preposição "de", que é selecionada pelo predicado na matriz. Nesse caso, é preciso observar que o sintagma-wh "quem" desloca-se da posição de complemento do verbo trazer, como se vê a seguir:

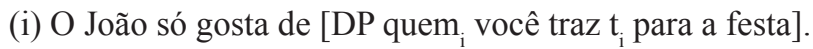

Observe-se que, nesse caso, a categoria do sintagma-Wh, um DP, (sintagma determinante) é compatível com a seleção da preposição (que precisa tomar um DP como complemento).

No caso de (2) b., é importante observar que o verbo na matriz seleciona uma preposição que também está relacionada ao predicado da subordinada. Note-se que a interpretação nesses casos é a de que a expressão com quem, o PP (ou o sintagma preposicional), portanto, se desloca como um todo para a fronteira da sentença subordinada, como se vê em (ii) a seguir:

(ii) Ele conversou [PP [com quem $]_{\mathrm{i}}$ eu saí $\left.\left.t_{\mathrm{i}}\right]\right]$.

Em Medeiros Junior (2005), apresenta-se análise interessante desse fenômeno, que o autor denomina crase de preposições idênticas. 
Em geral argumenta-se que em línguas com matching, uma falha na combinação resulta em sentenças mal formadas, como se pode ver em (4); (cf. BRESNAN; GRIMHAW, 1978; GROOS; RIEMSDIJK, 1981; HIRSHBÜHLER; RIVERO, 1983; SUÑER, 1984; VOGEL, 2001, 2002, 2003; MÓIA, 1996; MEDEIROS JUNIOR, 2005, 2006; MARCHESAN, 2008).

*O João visitou $\left[_{\mathbf{D P}}\left[{ }_{\mathbf{P P}}\right.\right.$ por quem a irmã se interessa $]$.

Boa parte da discussão sobre o fenômeno concentra-se na avaliação de relativas livres em posição de subcategorização, mas há também alguma discussão que enfoca esse tipo de sentença em posição de sujeito e é desse tipo de construção em especial que o presente trabalho busca tratar.

Alguns dos estudos relevantes sobre RLs em posição de sujeito argumentam que esse tipo de oração relativa apresenta comportamento distinto quanto ao matching, quando se consideram línguas pro-Drop e não pro-Drop. Estudos como os de Hirshbühler e Rivero (1983) para o catalão, Suñer (1984) e Grosu (1994) para o espanhol atestam categoricamente que em línguas de sujeito nulo a condição de matching não se aplica. É o que se pode observar no dado a seguir, adaptado de Grosu, 1994.

\section{ESPANHOL}

(5) Con quien me quiero casar vive a la vuelta 'with whom me want marry lives at the corner'

$\left(\right.$ GROSU, 1994) ${ }^{4}, 5$

A ideia é, portanto a de que em língua não pro-Drop o matching seja obrigatório, que é o que se vê em inglês, por exemplo:

\footnotetext{
${ }^{4}$ Mantém-se, nesse e em outros exemplos, a glosa original elaborada pelos autores nos textos citados, já que se trata de citações diretas. Para facilitar a leitura, as traduções para o português serão acrescentadas em notas de rodapé.

${ }^{5}$ Com quem quero me casar vive na esquina.
} 
(6) a. *He'll reach [NP [AP however tall] $]$ his father did.

b. *He'll get [AP [NP whatever height] his father did.

(BRESNAN; GRIMSHAW, 1978) ${ }^{6}$

O português do Brasil (PB) parece apresentar um contraste interessante no que concerne a RLs em posição de sujeito:

(7) a. $\left[_{\mathbf{D P}}\left[{ }_{\mathrm{PP}} *\right.\right.$ De quem $]$ o Pedro não gosta $]$ veio para jantar.

b. $\left[_{\mathbf{D P}}[\mathbf{P P} *\right.$ Com quem] o João falou $]$ possui um apartamento na Paulista.

c. $\left[{ }_{\mathrm{DP}}\left[{ }_{\mathrm{PP}}\right.\right.$ *Por quem $]$ a Maria se interessa $]$ comprou um carro novo.

(8) a. $\left[_{D P}\left[{ }_{P P}\right.\right.$ De quem] o João gosta] é um mistério insondável.

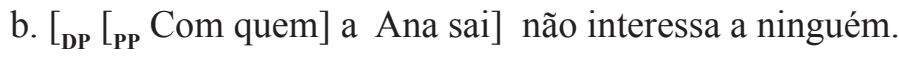

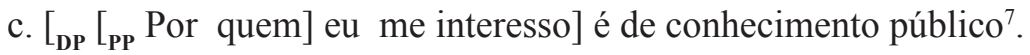

Como se vê, o PB parece apresentar um interessante paradoxo: na posição de sujeito, RLs devem combinar (dados em (7)), ou podem não apresentar o efeito de compatibilidade (dados em (8)).

É, portanto, objetivo deste trabalho discutir as razões do contraste entre (6) e (7), a saber, a possibilidade do alçamento da preposição em (7), mas não em (6), bem como traçar uma linha de análise que providencie argumentação convincente para uma distinção entre as construções em (6) e (7), embora elas se mostrem inicialmente análogas.

${ }^{6}(6) *$ Ele vai chegar a quão quer que alto seu pai tenha chegado

${ }^{7} \mathrm{O}$ que se busca evidenciar em (7) e (8) é a compatibilidade (ou incompatibilidade) entre a categoria sintática esperada na matriz (um DP - sintagma determinante (ou sintagma nominal, em termos mais simples) e a categoria que de fato aparece nessa posição: um PP (sintagma preposicional). O intrigante nos dados é que a expectativa é a de que o efeito fosse o mesmo: se a categoria não combina, a sentença deveria ser rejeitada, contrariamente aos fatos. 
O fenômeno é aqui abordado na perspectiva da gramática gerativa, considerada em seu desdobramento mais recente, que é denominado teoria de princípios e parâmetros. A hipótese chomskiana para o fenômeno da linguagem é a de que as línguas são afetadas por universais linguísticos, princípios comuns a toda e qualquer língua natural, e parâmetros específicos, que são os elementos responsáveis pela existência de variação entre essas muitas línguas. Muito da análise feita a partir dessa perspectiva vai, portanto, apresentar caráter comparativo, já que o que se pretende é atingir uma descrição generalizante da competência linguística dos falantes em geral.

Nesse sentido, os dados aqui analisados serão constantemente comparados às ocorrências do fenômeno em outras línguas (românicas ou não), para que se possa atingir uma descrição das características do fenômeno em português do Brasil (PB).

O texto se estrutura da seguinte maneira: na seção 2, a seguir, construo uma discussão sobre a natureza de relativas livres em posição de sujeito, efeitos de compatibilidade e analiso hipóteses anteriores. A seção 3 traz uma análise dos dados do português e na seção 4 apresento a proposta de análise que procuro apresentar aqui.

\section{RLs em posição de sujeito: qual é de fato o ponto?}

\subsection{Algumas Análises (Suñer (1983, 1984) e Harbert (1983)}

Conforme se argumentou na seção anterior, as opiniões se dividem quando a questão é RLs em posição de sujeito. Trabalhos como os de Suñer $(1983$, 1984) e Harbert (1983) - ambos constituídos com base na hipótese do $\mathrm{COMP}^{8}$ para a análise de RLs - propõem que línguas que

\footnotetext{
${ }^{8}$ A hipótese de acessibilidade do COMP, formulada em Gross e Riemsdijk (1981), propunha uma dupla possibilidade estrutural para RLs: uma com o sintagma-wh em COMP, com o antecedente vazio e outra com a palavra-wh localizada no núcleo do sintagma antecedente. Diversamente do que afirmavam Bresnan e Grimshaw (1978) em sua hipótese de base segundo a qual sintagmas-wh em RLs seria gerados na base, externamente ao $\mathrm{CP}$, na posição do antecedente da sentença relativa, a proposta de Gross e Riemsdijk prevê que o matching é possível mesmo em línguas em que se considera o núcleo do COMP como sendo a posição em que se encontra a palavra ou
} 
permitem sujeitos nulos também permitem RLs sem matching na posição de sujeito. Em línguas de sujeito não nulo o matching é obrigatório.

Essa dicotomia parece se aplicar bem às línguas eslavas, como mostram os dados a seguir, adaptados de Izvorski (1997):

\section{BÚLGARO}

(9) a. $\left[_{\mathbf{R L}} \mathrm{S}\right.$ kogoto govoriš $]$ pečeli sânstezanieto.

'with whom speak-2sg wins the-race'

Whoever you speak with wins the race

b. $\left[_{\text {RL }}\right.$ Kogoto celuneš] pečeli sânstezanieto.

'Who-ACC kiss-2sg wins the-race

Whoever you kiss wins the race ${ }^{9}$

\section{POLONÊS}

(10) a. $\left[_{\mathbf{R L}} \mathrm{Z}\right.$ kimkolwiek porozmawiasz] zrozumie ci®. 'with whoever wiil-talk-2sg will-understand-3sg you'

Whoever you talk to will understand you.

sintagma-wh. Nesses casos, seria o próprio sintagma-wh e não a categoria nominal vazia que antecede a relativa o elemento relevante para a satisfação dos requerimentos da matriz. Nos casos em que se considera que o sintagma-wh se encontre em COMP, ele pode ser acessado nessa posição para a satisfação dos requerimentos da matriz. É como se o CP de RLs fosse transparente e não servisse de barreira para o acesso do predicador mais alto.

${ }^{9}$ (9) a. Quem quer que você fale com vence a corrida.

b. Quem quer que você beije vence a corrida. 


b. [RL $_{\text {RL }}$ Kogo nie zapytasz $]$ wskże ci drog॰.
'Who-ACC not will-ask-2sg will-show-3sg you way'
Whoever you ask will show you the way ${ }^{10}$.

(IZVORSKI, 1997)

A análise desenvolvida em Suñer $(1983 ; 1984)$ propõe que o núcleo não realizado fonologicamente de uma RL seja pro. Disso decorre que, como essa categoria vazia necessita ser determinada, em RLs sujeito, atinge-se a determinação de pro por meio de case matching.

Assim, a ideia geral que se formula é a seguinte: em línguas proDrop, quando a RL está em posição de sujeito, pro já é automaticamente determinado por Infl; nesses casos, a condição de case matching não é requerida. Entretanto, em línguas não pro-Drop, em que o Infl não pode determinar a categoria pro, a condição de matching deve se aplicar, para que uma sentença seja bem formada.

A análise de Harbert (1983) caminha em direção semelhante com a diferença de que, segundo essa proposta, a categoria vazia em RLs é PRO e não pro. ${ }^{11} \mathrm{~A}$ ideia geral dessa hipótese é que PRO é o núcleo de uma relativa livre com matching. Como se sabe, $\mathrm{PRO}$ não pode ser regido; não pode, portanto, satisfazer os requerimentos do núcleo regente na matriz. Assim sendo, o sintagma-Wh em COMP é quem deve satisfazer os requerimentos da matriz. Vale ressaltar que esse tipo de análise se baseia numa natureza digamos transparente de Comp nesse tipo de estrutura sintática.

Um dos principais problemas que esse tipo de análise tende a apresentar parece ser a estipulação de uma variabilidade estrutural para RLs, a depender da posição sintática que essa sentença ocupe - numa

${ }^{10}(10)$ a. Quem quer que você fale com vai entender você.

b. A quem quer que você peça vai te mostrar o caminho.

${ }^{11}$ À guisa de esclarecimento, as designações PRO e pro, na teoria gerativa referem-se a categorias vazias, sendo que PRO é associado a formas verbais não finitas, enquanto pro está relacionado a formas flexionadas. Segundo essa visão, pro é uma categoria que precisa ser determinada, sob pena de não ser licenciada. 
mesma língua ou em línguas diferentes. Esse tipo de problema já havia sido apontado em Izvorski (1997).

Além disso, nem a hipótese de Suñer nem tampouco a de Harbert parecem fornecer uma explicação razoável para o que parece estar ocorrendo no PB, língua em que RLs em posição de sujeito parecem às vezes apresentar matching e ás vezes não.

Outra questão que os estudos anteriores sequer consideram é o fato de algumas línguas com matching obrigatório adotam estratégias variadas para se livrar do mismatching, quando não ocorre a compatibilidade necessária em RLs em posição de subcategorização ou em posição de sujeito tal como observado em Vogel (2001, 2002, 2003) e Medeiros Junior (2005), situação em que um dos elementos atribuidores de Caso (às vezes o que se encontra na matriz) é apagado, para que se garanta uma espécie de compatibilidade. ${ }^{12}$ Nesses casos seria, por exemplo, complicado analisar tais sentenças à luz de uma proposta como a de Harbert, por exemplo.

A esse tipo de visão opõem-se trabalhos como o de Izvorski (1997), que passo a analisar na subseção que segue.

\subsection{A análise de Izvorski (1997)}

Izvorski (1997) aborda a questão das RLs sujeito de maneira diversa. A autora atesta que o matching só se mostra obrigatório quando a RL ocupa posição argumental. Segundo essa visão dos fatos, sentenças com sujeito sem matching e aquelas com matching obrigatório apresentam uma sintaxe diferente.

A ideia básica é que sentenças com sujeitos sem matching envolvem uma RL deslocada à esquerda e um pro resumptivo dentro do TP; tais RLs são isentas do requerimento de matching, porque são geradas na base, do lado de fora do IP e, portanto, em posição não argumental.

O diagrama a seguir apresenta a proposta estrutural para as RLs deslocadas à esquerda.

\footnotetext{
${ }^{12}$ Conferir dado em (2)b.
} 
(11)



Por seu turno, RLS em posição argumental (sujeito, por exemplo) ou ligadas a uma posição argumental por meio de movimento devem exibir compatibilidade, ou seja, precisam combinar; ${ }^{13}$ o diagrama abaixo mostra a estrutura de RLs com matching obrigatório.

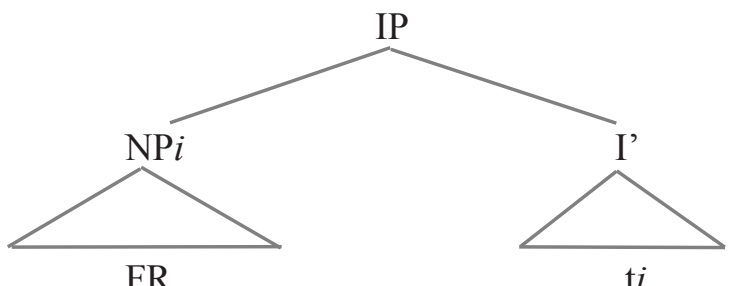

FR

De acordo com essa proposta, a configuração (11) só está disponível em línguas de sujeito nulo, enquanto (12) deve ser associada a línguas não pro-Drop.

Assim, a posição de sujeito em si não é a questão, mas a posição em que a RL é gerada, dependendo do tipo de língua que se está analisando.

A pergunta agora é: e quanto ao PB? Podem-se associar as duas estruturas à língua? Se assim o fizermos, temos o problema posto em 1. Mas há algo bem interessante nos dados da língua. Passemos à análise do que pode estar ocorrendo em português do Brasil.

\footnotetext{
${ }^{13}$ A previsão que faz essa análise é a de que sujeitos pós-verbais desse tipo também precisariam estar sujeito aos efeitos de compatibilidade ou (combinação) nesses casos.
} 


\section{Analisando os dados do PB}

Na seção inicial, vimos um paradoxo que parece afetar os dados do português do Brasil: algumas RLs em posição de sujeito precisam combinar e outras não. Será que existe uma solução para esse paradoxo, ou se trata de uma oposição aparente? Seriam as sentenças do português que não apresentam o matching casos típicos de orações relativas livres?

Há razões para acreditar que as sentenças em (8), apesar das aparências, não são de fato RLs. Vou tentar argumentar que elas são na verdade, perguntas indiretas. Passemos à avaliação detida dos fatos.

\subsection{Da ambiguidade entre relativas livres e interrogativas indiretas}

Orações relativas livres e interrogativas indiretas têm sido alvo de muitas investigações em diversas línguas, principalmente por se mostrarem ambíguas em função de características semelhantes:

1. Apresentam-se (ambas) como sentenças encaixadas (subordinadas);

2. São introduzidas por um pronome-wh cuja forma é a mesma em sua natureza interrogativa e relativa (quem, quando, como...).

Estudos como os de Alvarenga (1981), Cohen (1990), Rocha (1990) e Medeiros Junior (2005), debruçam-se sobre a questão para procurar elencar argumentos que demonstrem as diferenças estruturais entre esses dois tipos de construção sintática.

Segundo Alvarenga (1981) e Rocha (1990), uma propriedade de perguntas indiretas no PB que as distingue de relativas livres é o fato de se poder clivar o sintagma-wh nessas construções, por meio da inserção da expressão é que logo após o sintagma-wh, como se vê em A, a seguir, procedimento que é proibido em relativas livres, como se mostra em B:
A. O João quer saber quem (é que) pegou o dinheiro no cofre.
B. Ele encontrou na festa quem *(é que) você conhece.

Cohen (1990), por seu turno, propõe que o ponto de diferenciação entre essas construções seja dado em termos das propriedades de seleção 
do verbo na matriz, análise que é compatível com a de Rizzi (1997), para quem o CP de uma interrogativa indireta é portador de um traço [+wh] (uma espécie de traço interrogativo), que é diretamente selecionado pelo predicado mais alto. Assim, um verbo como perguntar seleciona uma sentença (um CP) de valor interrogativo (o que se vê em C), enquanto um verbo do tipo de selecionar (que aparece em D) seleciona uma proposição sem o traço interrogativo.

C. O Pedro perguntou $\left[_{+w h}\right.$ [quem você viu / de quem você gosta]].

D. O recrutador selecionou $\left[_{-w h}\right.$ [quem se saiu melhor $]$.

Medeiros Junior (2005) argumenta que o núcleo $\mathrm{C}^{0}$ de uma interrogativa indireta pode ser preenchido com o morfema "que" em oposição ao que ocorre com uma relativa livre. Para esse autor, o morfema "que" é a realização morfológica do traço [+wh] proposto por Rizzi, que não estaria presente no $\mathrm{CP}$ da relativa livre. ${ }^{14} \mathrm{E}$ o que se vê em $\mathrm{E}$ e F a seguir;

E. Ele quer saber quem que chegou atrasado.

F. *Nós convidamos quem que você indicou

Nas seções a seguir, tento constituir argumentos em função de provar que as sentenças bem formadas de (8) não podem ser consideradas relativas livres em posição de sujeito, mas perguntas indiretas em posição de tópico. Vejamos essa questão em detalhes.

\subsection{O pied-piping da preposição}

Uma análise atenciosa mostrará que as sentenças em (7) permitem o pied-piping da preposição, enquanto RLs comuns no PB parecem bloqueá-lo. A questão da impossibilidade do pied-piping da preposição

\footnotetext{
${ }^{14}$ Medeiros Junior (2005) ainda propõe que a impossibilidade desse preenchimento em relativas livres tem conexão com o fato de haver uma incorporação dos núcleos sintáticos $\mathrm{C}^{0} \mathrm{e} \mathrm{D}^{0}$, o que indisponibiliza o núcleo $\mathrm{C}^{0}$ para a realização de que. Para mais detalhes, conferir Medeiros Junior (2005).
} 
em PB já fora atestada nos trabalhos de Medeiros Junior (2005; 2006; 2009) e verificada nos dados de aquisição por Lessa de Oliveira (2009).

Assim sendo, RLs legítimas bloqueiam o pied-piping da preposição, como se vê em (13) e (14), em que esse procedimento resulta em sentenças mal formadas.

(13) *Ele convida (para as festas) [de quem $]_{\mathrm{i}}$ você gosta $t_{\mathrm{i}}$

(14) *Com quem o João falou possui um apartamento na Paulista.

Observe-se que em PB, tal como observado em Medeiros Junior (2005), interrogativas indiretas, em oposição a RLs, autorizam o piedpiping da preposição. Esse procedimento em sentenças interrogativas é perfeitamente viável e produz sentenças convergentes. É o que se vê em (15).

(15) Ele perguntou [[de quem $]_{i}$ você gosta $\left.t_{i}\right]$ (pergunta indireta)

Isso nos põe algumas dúvidas quanto à natureza sintática das sentenças em (7). Seriam elas de fato RLs? Na subseção a seguir, procuro apresentar mais um argumento em favor da não interpretação de sentenças do tipo de (7) como relativas livres comuns. Vejamos.

\subsection{Clivagem}

Como se mostrou em 3.1, as sentenças de (8) permitem a clivagem do sintagma-Wh, como se vê em (16). Observe-se que esse procedimento é viável em perguntas indiretas (18), mas não em RLs (17).

(16) a. Por quem é que eu me interesso é de conhecimento público.

b. Com quem é que a Ana sai não te interessa.

(17) a. Quem lê Guimarães Rosa é inteligente. (Relativa Livre)

b. *Quem é que lê Guimarães Rosa é inteligente 
(18) a. Ele perguntou quem lê Guimarães Rosa. (Pergunta Indireta)

b. Ele perguntou quem é que lê Guimarães Rosa. ${ }^{15}$

Um trabalho de Mioto e Negrão(2007) argumenta consistentemente que a construção de sentenças clivadas é possível em contextos de interrogativas, mas não de relativas. Para esses autores, questões sintáticas mostram que sentenças clivadas não podem conter uma relativa. Se Mioto e Negrão estiverem certos, eis a razão por que a clivagem é impossível quando se tem RLs, contrariamente ao que acontece quando o assunto é uma pergunta indireta.

Temos, portanto, mais um argumento em favor de não considerar as sentenças em (7) como RLs legítimas. Mas isso ainda não é tudo; há ainda mais alguns argumentos em favor da hipótese que se levanta aqui. Passemos a eles.

\subsection{O efeito do Comp duplamente preenchido}

Outro argumento em favor da não categorização dos dados em (8) como RLs (também aventado em 3.1) vem da seguinte questão: sentenças em (8) autorizam a realização fonológica do núcleo $\mathrm{C}$ da subordinada (como se vê em (19a e b)), fato que, segundo Medeiros Junior (2005), é possível em interrogativas indiretas (20a), mas não em RLs (20b). Analisemos os dados em (19) e (20) a seguir.

(19) a. Por quem que eu me interesso é do conhecimento público.

b. Com quem que a Ana sai não é da sua conta.

(20) a. Ele perguntou [ ${ }_{C P}$ quem [ ${ }_{C}$ que lê Guimarães Rosa $\left.]\right]$. (Pergunta Indireta)

b. ${ }^{*}\left[_{\mathbf{C P}}\right.$ Quem $\left[_{\mathbf{C}}\right.$ que lê Guimarães Rosa $\left.]\right]$ é inteligente (Relativa Livre)

Observe-se que, em perguntas, é possível associar dois elementoswh à posição conhecida como COMP (em linguagem moderna, o CP). Temos aí o sintagma-wh, que se supõe ocupar a posição de especificador

\footnotetext{
${ }^{15}$ Discussão sobre esse tipo de possibilidade em interrogativas indiretas pode ser achada em Alvarenga (1981).
} 
e o termo que, que se encontra no núcleo C. ${ }^{16}$ Esse procedimento, como se observa em 20b, é inviabilizado em RLs.

Medeiros Junior $(2005,2006)$ atribui essa impossibilidade à composição estrutural de RLs que, segundo esse autor, envolvem uma espécie de amálgama sintático entre os núcleos $\mathrm{C}$ e $\mathrm{D}$ envolvidos no processo de relativização; algo como um procedimento de incorporação de núcleos, tal como avaliado em Baker (1988), procedimento sintático que tem impacto direto na morfologia, considerando-se a forma morfológica do sintagma-wh. ${ }^{17} \mathrm{~A}$ impossibilidade da inserção do termo "que" no Comp de RLs seria inviabilizada por uma indisponibilidade do núcleo naquela posição, já que se entende que tenha se incorporado a D.

A análise de tais questões sugere (mais uma vez) que o que de fato se passa aqui é que as sentenças em (8) parecem muito mais se comportar como interrogativas indiretas do que propriamente com relativas livres. Vejamos um último argumento em função dessa análise.

\subsection{Semântica}

A questão da interpretação semântica de sintagmas-wh que integram RLs tem sido abordada em diversos estudos sobre o tema. A proposta mais corrente prevê que RLs apresentem uma interpretação maximizante, ${ }^{18}$ seja quando aponta uma totalidade, seja quando designa um indivíduo de uma espécie (cf. GROSU; LANDMAN, 1998).

\footnotetext{
${ }^{16}$ Para um debate mais aprofundado sobre a questão, cf. Kato e Nunes (2009).

${ }^{17}$ Consultar Medeiros Junior $(2005,2006)$ para avaliação detalhada dessa análise.

${ }^{18}$ Semanticamente, entende-se que a interpretação do sintagma-wh em RLs sofra uma operação de maximização, a qual supõe que o conteúdo semântico da oração relativa seja o que mais importa para que se chegue á interpretação geral da sentença (cf. Grosu e Landman 1998). Essa operação força um tipo específico de leitura: a de que o indivíduo representado pela variável (o termo-wh) obtenha uma interpretação plural maximizante (ou máxima). Contrariamente ao que ocorre em relativas comuns com um antecedente, em que a interpretação é dada pelo conteúdo semântico-pragmático da entidade que o antecedente representa. Vejamos:

(i) Ele conheceu os atletas que participaram da meia-maratona.

(ii) Refiro-me ao pacote de medidas econômicas, que não me parece resolver muita coisa.
}

(iii) Ele come o que colocamos na mesa. 
Quanto ao PB, de acordo com Medeiros Junior (2005), RLs exibem uma leitura preferencialmente universal para o sintagma-wh que as integra, enquanto perguntas indiretas apresentam uma leitura existencial para esses elementos.

Observemos com atenção o dado em (21). A interpretação para a palavra-wh é necessariamente a de quem quer que. Dizendo de outro modo, a interpretação para o vocábulo quem na sentença relativa precisa estar baseada numa visão universal, isto é, que se possa aplicar a qualquer indivíduo que venha a se sentar na cadeira. Quem quer que sente naquela cadeira é entrevistado pelo Jô; ou: O Jô entrevista quem quer que sente naquela cadeira.

(21) O Jô entrevista quem senta naquela cadeira. ${ }^{19},{ }^{20}$

Observe-se que em (i), a interpretação da sentença se dá na interseção entre o conjunto dos atletas e o conjunto daqueles que venceram a prova (conferir De Vries 2002 e Marchesan 2012), ou - como o quer Medeiros Junior (2015), na criação de um subconjunto (o dos que venceram) dentro do conjunto maior (o dos atletas).

Em (ii), o mais importante na interpretação da sentença é o conteúdo da expressão "pacote de medidas econômicas", à qual se associa a relativa, coordenando à ideia principal uma informação adicional (cf. De VRIES, 2002).

Já o que temos em (iii) (contexto em que a subordinada é uma relativa livre) é o que se chama operação de maximização: o conteúdo de "o que colocamos na mesa" é o mais relevante para a interpretação do enunciado e a referência para [o que] é o que quer que, o que quer que seja que, o que faz que se entenda o conjunto de possibilidades de referências para a variável como plural e máximo.

${ }^{19}$ Cabe ressaltar que mesmo em construções com formas verbais télicas, que remetam a uma ação efetivamente concluída e não iterativa, como em (21), a mesma interpretação digamos universal se aplica ao sintagma-wh de relativas livres. Vejamos:

(i) O Jô entrevistou quem escreveu esse livro.

Imaginemos que o enunciador da sentença continue seu discurso: "Eu não sei como é o nome do escritor, mas enfim... foi o escritor do livro que o Jô entrevistou; quem quer que seja que ele tenha entrevistado, a pessoa entrevistada escreveu esse livro.

Como se vê, mesmo em contextos altamente específicos, a associação da interpretação universal para o sintagma-wh é possível. Cf. Medeiros Junior (2014) para uma análise dessa possibilidade como uma propriedade morfo-semânica de sintagmas-wh em relativas livres.

${ }^{20}$ Para mais uma discussão sobre a semântica de RLs, ver Caponigro (2001). 
$\forall \mathrm{x}, \mathrm{x}=$ uma pessoa [Jô entrevista $\mathrm{x}$ ]

Já em (22), situação em que se tem uma pergunta encaixada, o mesmo tipo de procedimento interpretativo não pode ser aplicado ao sintagma-wh que integra a subordinada. Aqui, caso se queira obter o resultado esperado, é necessário atribuir ao sintagma-wh uma interpretação absolutamente existencial: eu quero saber a identidade da pessoa que pegou o dinheiro na gaveta. Ou seja: alguém pegou o dinheiro da gaveta, uma pessoa, e eu quero saber quem é essa pessoa.

Nesses casos, como se vê em (24a e b), a inserção da expressão quer que (que orienta uma leitura universal para o sintagma-wh na sentença) é completamente proibida.

(22) Eu quero saber quem pegou o dinheiro na gaveta.

$>\quad \exists x, x=$ uma pessoa [Eu quero saber quem é $x$ ]

(23) Por quem eu me interesso é de conhecimento público ${ }^{21}$.

$>\quad \exists x, \mathrm{x}=$ uma pessoa [Eu em interesso por $\mathrm{x}$ e $\mathrm{x}$ é do conhecimento público]

${ }^{21}$ Observemos detidamente o que ocorre em (i) logo abaixo:

(i) [Quem é corrupto] é de interesse do todo o povo.

Note-se que, nesse caso, como ocorre uma compatibilidade entre a categoria que encabeça a relativa livre (já que quem é um sintagma nominal) e a categoria que é esperada na posição de sujeito da oração matriz (um NP/DP também), a presente análise prevê que o que se mostra aí é de fato uma oração relativa livre em posição de sujeito. Nesse caso, portanto, a interpretação para o sintagma-wh que integra a sentença passa a ser universal, como já se previa antes: Quem quer que seja corrupto é de interesse de todo o povo.

O ponto relevante aqui é notar que tanto (23), quando a sentença em (i) são bem formadas, enquanto (14), repetida a seguir como (ii), não é:

(ii) [*Com quem o João falou] tem um apartamento na Paulista.

$\mathrm{O}$ que faria então a diferença entre (i) e (ii)? O fato de que em (i) a relativa livre é compatível com a categoria da posição que ocupa, enquanto em (ii) isso não ocorre. Mas em (23), que se esperaria ocorrer algo semelhante ao que ocorre em (ii), isso não acontece. Esse contraste fortalece a hipótese de que temos uma pergunta indireta em (23) com interpretação existencial para o sintagma-wh. 
(24) a.*Eu quero saber quem quer que pegou/ tenha pego o dinheiro na gaveta.

b.??? Por quem quer que eu me interesse é do conhecimento público.

Um olhar mais detido para as sentenças em (8) pode revelar que, para que se obtenha o resultado esperado, deve-se ler o wh com referência existencial. seguir:

Um argumento adicional pode ser dado com os enunciados a

(25) A resposta para a pergunta De quem o João gosta é de conhecimento público.

(26) A resposta para a pergunta Com quem a Maria sai não é da sua conta. ${ }^{22}$

Considerando todos esses fatos, somos levados a concluir que as sentenças que aparecem em (8) comportam-se muito mais como interrogativas indiretas do que como RLs, propriamente. Com base nessa ideia, passo a propor, na seção seguinte, o que entendo estar de fato acontecendo quanto aos dados postos em análise nesse trabalho.

\section{Proposta}

Conforme argumentos na seção anterior, o comportamento sintático das sentenças que aparecem em (8) se emparelha muito mais com o de perguntas indiretas do que com o de relativas livres em português do Brasil.

\footnotetext{
${ }^{22}$ Um problema para essa hipótese (tal como apontado por um dos revisores anônimos) é a possibilidade de que para uma construção como a que se mostra em (i), a seguir, a interpretação dada ao sintagma-wh possa ser a universal:

(i) Com quem a Maria sai não é da sua conta.

(ii) Com quem quer que seja que a Maria sai não é da sua conta.

Trata-se de fato de algo intrigante que talvez esteja relacionado à semântica do verbo "sair", que contém uma noção iterativa. Talvez esse problema fosse minimizado, mas não totalmente resolvido, se a forma verbal na subordinada fosse outra:

(iii) Com quem a Maria se casou não é da sua conta.

Essa questão fica em aberto para investigações futuras.
} 
Como se evidenciou, pontos como a clivagem, o pied-piping da preposição, a possibilidade de inserir o termo que no núcleo de perguntas e das sentenças em (8) e a impossibilidade desse procedimento em RLs ou mesmo as questões referentes à interpretação apontam para uma maior possibilidade de se interpretar as subordinadas dos dados em (8) como perguntas encaixadas e não como RLs. Passo a admitir daqui em diante que isso esteja correto. Isto posto, resta discutir a sintaxe dessas sentenças.

Comecemos inicialmente por investigar a questão do matching em RLs. A pergunta inicial é: o português é mesmo uma língua que apresente sentenças com e sem matching? Se isso é verdade, que tipo de sentença precisaria apresentar matching e quais as que dispensariam tal requerimento?

Em Medeiros Junior (2005), apresenta-se a seguinte análise: o $\mathrm{PB}$ apresenta RLs com uma forma verbal realis (as finitas) e outras com um verbo com traço irrealis (as infinitivas e as subjuntivas). Segundo a análise de Medeiros Junior, apenas relativas livres realis precisam obedecer ao requerimento de matching, algo totalmente dispensável em sentenças infinitivas ou subjuntivas. É o que se pode ver nos dados a seguir.

O João não tem [DP [PP com quem conversar]].

(28) Não há [DP [PP do que a Maria não se queixe]].

Marchesan e Mioto (2009) argumentam contrariamente a essa análise definindo o PB como uma língua de matching obrigatório e propondo que infinitivas do tipo das que se vê em (28), por seu comportamento sintático, não podem ser consideradas relativas livres. A mesma análise os autores estendem para as sentenças infinitivas, como (27).

De fato, conforme já observado em Medeiros Junior (2006), em diversos contextos do português onde ocorre um, digamos, mismatch entre os requerimentos da matriz e a forma do sintagma-wh da subordinada, a língua opta por procedimentos que buscam se livrar da incompatibilidade para garantir o matching, procedimento exatamente idêntico ao de muitas línguas de matching obrigatório.

Sejam os dados: 
(29) a. *A Maria só conversa com de quem ela gosta.

b. *O João conhece com quem você saiu.

Não é incomum encontrarmos no PB construções como as que aparecem em (30), em que a língua apresenta uma opção ao mismatching:

(30) a. A Maria só conversa com quem ela gosta.

b. O João conhece quem você saiu com ele.

Muito frequentes no vernáculo, as construções em (30) mostram que, em face do conflito de Caso evidenciado em (29), o apagamento do marcador de Caso da subordinada configura-se como uma estratégia alternativa para resolver o conflito em (29a). Sem o outro elemento que concorra com o predicador da matriz, o conflito se resolve e a derivação da sentença é possível.

Além disso, observa-se na língua também uma alternativa resumptiva - caso do dado em $30 \mathrm{~b}$ - que também resolve o problema da incompatibilidade de requerimentos entre os elementos na matriz e na subordinada. Como se pode ver, o pronome resumptivo satisfaz os requerimentos do predicado mais baixo e a RL como um todo satisfaz as exigências do predicador na matriz.

Além desse tipo de estratégia, a língua também adota algumas outras estratégias alternativas para se livrar do conflito, como a correlativização, por exemplo, ${ }^{23}$ o que nos leva a crer que Mioto e Marchesan parecem mesmo ter razão quanto ao matching em PB.

Passo a assumir com esses autores que o PB seja uma língua de $100 \%$ matching. Resta-nos propor, então, uma análise estrutural para os dados em (8).

Eis o que já sabemos:

1. As sentenças subordinadas em (8) são perguntas indiretas;

2. O PB é uma língua com matching obrigatório e as sentenças convergentes em que ele não ocorre não podem ser chamadas RLs.

${ }^{23}$ Para um detalhamento maior dessa proposta, cf. Medeiros Junior (2005). 
Assim, qual a análise estrutural viável para as sentenças "subjetivas" em (8)?

Se observarmos com atenção, as sentenças em (8) apresentam várias das características de um tópico:

I - É possível estabelecer uma pausa entre a sentença "subjetiva" e o resto da estrutura, como se tentou representar em (31)

II -É possível que se empregue um resumptivo retomando a informação da sentença "subjetiva", como se vê em (31);

III - É possível uma interpretação segundo a qual algo como o que se mostra após a vírgula em (32) seja o comentário atribuído ao tópico (a sentenças subjetiva).

(31) De quem o João gosta, é um mistério insondável.

(32) De quem o João gosta, isto não é da sua conta.

Desse modo, passo a assumir que o que temos nos dados convergentes de (8) sejam sentenças interrogativas em posição de tópico, com um resumptivo nulo na posição de sujeito da matriz, algo que se aproxima da hipótese de Izvorski (1997), salvaguardadas as devidas distinções.

A ideia geral é a de que em (7) tenhamos RLs genuínas, para as quais o requerimento de matching é obrigatório, contrariamente ao que acontece em (8). Os dados em análise aqui constituem a estrutura em (33) e o diagrama em (34).

(33) $\left[_{\mathrm{CP}}\left[_{\mathrm{TopP}}\right.\right.$ De quem o João gosta $\left[_{\mathrm{TP}}\right.$ pro [é um mistério insondável]. 


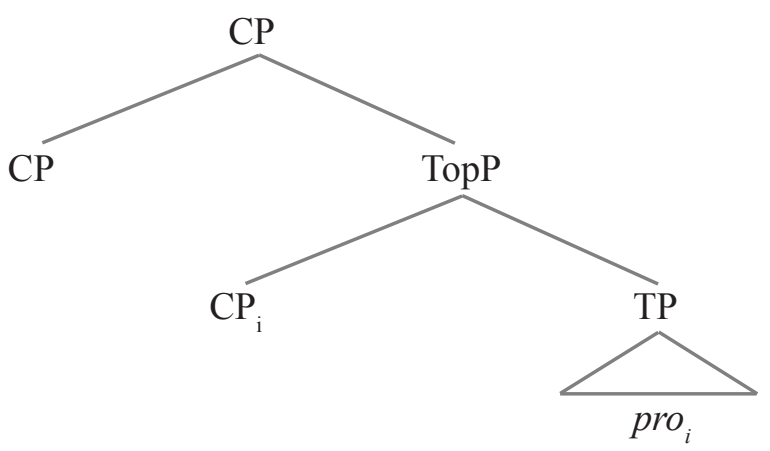

Fica em aberto a discussão de sentenças como a que se mostra em (35) (nas quais não parece ocorrer o matching), que ainda apresentam uma dificuldade para a proposta que por ora se constrói. Essa discussão deverá ser retomada em trabalhos futuros.

(35) a. Eu me desliguei de com que tava falanado e disse que o João trai a mulher.

b. Ele não faz a menor ideia de com quem a filha sai.

c. ?Minha mão nem sonha com por quem eu me interesso.

\section{Considerações finais}

A análise dos dados do PB revelou que orações relativas livres nessa língua precisam se submeter necessariamente ao efeito de compatibilidade (mesmo as que se encontram em posição de sujeito), o que ficou claro pelo fato de a língua apresentar algumas estratégias para se livrar do conflito (categorial ou de Caso) quando ele ocorre. Por essa visão, entendemos que a generalização proposta em trabalhos como os de Suñer $(1983,1984)$ e Harbert (1983), que prevê que RLs em línguas pro-Drop ${ }^{24}$ não precisam se submeter ao efeito de compatibilidade, não parece estar correta.

\footnotetext{
${ }^{24}$ Uma questão que fica aqui em aberto é a que concerne ao fato de o PB estar perdendo a característica de língua pro-Drop, tal como proposto em Duarte (1993). Avaliações sobre essa questão e as possíveis consequências para a presente análise ficam em aberto para trabalhos futuros.
} 
A análise do comportamento sintático de sentenças como as que aparecem no dado em (8) mostrou que não temos - nesse contexto - relativas livres em posição de sujeito, mas sim perguntas indiretas em posição de tópico. Questões como a possibilidade de se fazer o piedpiping, ou mesmo a possibilidade de realização de clivagem, ou ainda a possibilidade de ter o COMP duplamente preenchido nessas sentenças, conduziu-nos à dedução de que as sentenças-wh em (8) não podem se tratar de RLs, constituindo perguntas que se encontram topicalizadas.

A avaliação mais detida de dados como os de (35) fica em aberto para estudos futuros do fenômeno.

\section{Referências}

ALVARENGA, D. Sobre interrogativa indireta no português. Dissertação (Mestrado) - Universidade Federal de Minas Gerais - UFMG, Belo Horizonte, MG, 1981.

AXT, M. Condutas cognitivas e estratégias de processamento de orações relativas por crianças entre 6 e 13 anos. Psicologia: reflexão e crítica, Porto Alegre, v. 5, n. 1, p. 43-54, 1992.

BAKER, M. Incorporation. Chicago: The University of Chicago Press, 1988. BRESNAN, J.; GRIMSHAW, J. The syntax of English free relatives. Linguistic Inquiry, v. 9, p. 331-391, 1978.

CAPONIGRO, I. On the semantics of indefinite free relatives. In: KOPEN, M. v.; SIO, J.; De VOS, M. (Ed.). Proceedings of ConSOLEX. Leiden: SOLE, 2001. p. 49-62.

CHOMSKY, N. Lectures on government and binding. Dordrecht: Forris, 1981.

CHOMSKY, N. Knowledge of language. Its nature, origin and use. New York: Praeger, 1986.

CHOUPINA, M. C. M. G. Orações relativas: quando e como inseri-las na sala de aula. Exedra, v. 9, p. 49-68, 2010.

COHEN, M.A.A. M. Syntactic change in Portuguese: relative clauses and the position of the adjective in the noun phrase. 1990. Tese (Doutorado)Universidade Estadual de Campinas - Unicamp, Campinas, 1990. 
COHEN, M. A. A. M. Orações relativas restritivas em português registro formal e informal. 1981. Dissertação (Mestrado) - Universidade Federal de Minas Gerais - UFMG, Belo Horizonte, MG, 1981.

CORRÊA, W. R. Oração relativa: o que se fala e o que se aprende no português brasileiro. 1998. Tese (Doutorado) - Universidade Estadual de Campinas - Unicamp, Campinas, 1998.

De VRIES, M. The syntax of relativization. Utrecht: Lot, 2002.

DUARTE, Eugenia. Do pronome nulo ao pronome pleno: a trajetória do sujeito no português do Brasil. In: ROBERTS, Ian; KATO, Mary (Org.). Português brasileiro: uma viagem diacrônica. Campinas: Editora da Unicamp, 1993. p. 107-128.

GOMES DA SILVA, R. M. A gramática invisivel - o caso das orações relativas. 2007. Dissertação (Mestrado) - Universidade de Brasília, Brasília - UnB, 2007.

GROSS, A.; RIEMSDIJK, H. v. Matching effect in free relatives: a parameter of core. Helmut Burske Verlag, 1981. p. 119-162.

GROSU, A. Three studies in locality and case. Routlege: London, 1994. GROSU, A.; LANDMAN, F. Strange relatives of the third kind. Natural Language Semantics, v. 6, p. 125-170, 1998.

HARBERT, W. On the nature of matching parameter. The Lingusitic Review, v. 2, p. 237-284, 1983.

HIRSHBÜHLER, P.; RIVERO, M. L. Remarks on free relatives and matching phenomena. Linguistic Inquiry, v. 14, n. 3, 1983.

IZVORSKI, R. (Non-) Matching effects on free relatives and pro-Drop. In: PRZEZDZIECKI, M.; WHALEY, L. (Ed.). ESCOL'95. Cornell University, 1996. p. 89-102.

IZVORSKI, R. Subject free relatives in null-subject languages: evidence from Slavic. In: BROWNE, W.; DORNISCH, E.; KONDRASHOVA, N.; ZEC, D. (Ed.). Formal approaches to Slavic linguistics: the Cornell Meeting, 1997. p. 267-288.

KATO, M.; NUNES, J. A uniform raising analysis for standard and nonstandard relative clauses in Brazilian Portuguese. In: NUNES, J. (Org.). Minimalist essays on Brazilian Portuguese syntax. Philadelphia: John Benjamins Publishing, 2009. p. 93-120. 
MARCHESAN, A. C.; MIOTO, C. As relativas livres infinitivas no PB. In: Anais do XXIII Encontro Nacional da ANPOLL. UFG, Goiânia, GO, 2008.

MARCHESAN, Ani C. As relativas livres em português brasileiro e os efeitos de compatibilidade. 2008. Dissertação (Mestrado) - Universidade Federal de Santa Catarina - UFSC, Florianópolis, SC, 2008.

MEDEIROS JUNIOR, P. Sobre sintagmas-Qu e relativas livres no português. 2005. Dissertação (Mestrado) - Universidade de Brasília UnB, Brasília, 2005.

MEDEIROS JUNIOR, P. Relativas livres: uma proposta para o português. Revista de Estudos da Linguagem, Belo Horizonte, UFMG, v. 14, n. 2, p. 429-455, 2006.

MEDEIROS JUNIOR, P. Sobre orações relativas livres em posição de adjunto: considerações sintático-semânticas acerca das construções com quando e onde. Revista de Estudos da Linguagem, Belo Horizonte, UFMG, v. 17, v. 1, p. 51-71, 2009.

MIOTO, C.; NEGRÃO, S. As sentenças clivadas não contêm uma relativa. In: CASTILHO, A. T. de C. et alii (Org.). Descrição, história e aquisição do português brasileiro - estudos dedicados a Mary Kato. São Paulo: FAPESP; Campinas: Pontes Editores, 2007. p. 159-183.

MÓIA, T. A sintaxe das orações relativas sem antecedente expresso no português. In: Quatro estudos em sintaxe do português. Lisboa: Edições Colibri, 1996. p. 149-188.

PERRONI, M. C. As relativas que são fáceis na aquisição do português brasileiro. DELTA, São Paulo, v. 17, n.1, p. 59-79, 2001.

RIZZI, L. The fine structure of the left periphery. In: HAEGEMAN, L. (Ed.). Elements of grammar. Kluwer, Berkeley, 1997. p. 281-337.

SUÑER, M. Free relatives and the pro-drop head hypothesis. In: HARBERT, W. (Ed.). Cornell Working Papers 4: Papers from the Cornell Conference on Government and Binding Theory, June 1982, 1983. p. 223-248.

SUÑER, M. Free Relatives and the matching parameter. The Linguistic Review, v. 3, p. 363-387, 1984. 
VOGEL, R. Towards an optimal typology of the free relatives construction. IATL 8. In: GROSU, Alexander (Ed.). Papers from the Sixteenth Annual Conference and from The Research Workshop of the Israel Science Foundation The Syntax and Relative Clause Constructions Tel Aviv University, 2011. p. 107-119.

VOGEL, R. Free relative constructions in OT syntax. Resolving conflicts in grammars. In: FERRY, Caroline; FANSELOW, Gisbert (Ed.). Sonderheft optimality theory. Hamburg, 2002.

VOGEL, R. Surface matters. Case conflicts in free relative constructions and case theory. In: BRANDNER, Ellen; ZINSMEISTER, Heike. New perspectives on case theory. CSLI Publications, 2003. p. 269-299. 